\title{
Exploring Predictors of Social Actions by General Education Students towards Peers with Disabilities
}

\author{
Alicia Wyche Okpareke ${ }^{1} \&$ Christine L. Salisbury ${ }^{2}$ \\ ${ }^{1}$ School of Education \& Health Sciences, North Central College, Naperville, Illinois, USA \\ ${ }^{2}$ College of Education, University of Illinois at Chicago, Chicago, Illinois, USA \\ Correspondence: Alicia Wyche Okpareke, School of Education \& Health Sciences, North Central College, \\ Naperville, IL, USA.
}

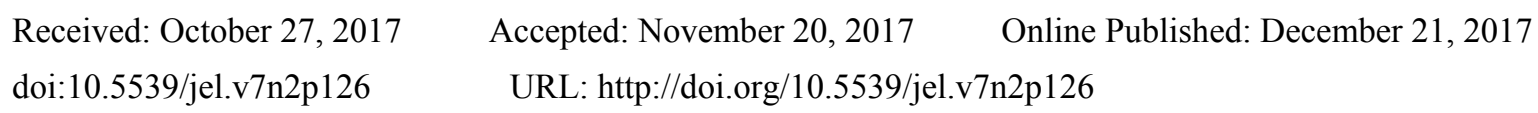

\begin{abstract}
This study deepens the field's understanding about factors that contribute to positive social engagement between students without disabilities and their peers with mild disabilities in general education classrooms. A sample of 68 seventh grade students with and without disabilities was drawn from general education classrooms in a suburban, Midwest district in the United States. Direct observation of students' social behavior, as well as student surveys and context measures, were used to explore associations among student attitudes, their perceived norms, feelings of efficacy, stated intentions and their actions towards peers with disabilities. Results revealed that students without disabilities strong intentions to interact with peers with disabilities were unrelated to their actual behavior. However, students' attitudes, norms, and feelings of efficacy were predictive of their intentions. Interpretations and implications for understanding the interplay of predisposing factors, intentions to socialize, and actual socializing behavior are discussed.
\end{abstract}

Keywords: inclusive classrooms, social behavior, students with disabilities

\section{Introduction}

In many of today's middle schools, students with mild disabilities are educated in the same classrooms as their peers without disabilities. These inclusive academic contexts afford opportunities for social interactions between students with disabilities (SWD) and their classmates without disabilities (SWOD). However, despite the potential for social engagement, research suggests that the frequency of interaction among peers with and without disabilities is generally low (Carter, Sisco, Brown, Brickham, \& Al-Khabbaz, 2008; Estell et al., 2008; Kavale \& Forness, 1996; Pearl et al., 1998) and SWD continue to experience less social acceptance, fewer positive social interactions, and be socially rejected relative to their classmates without disabilities (Dyson, 2003; Estell et al., 2008; Hamovitch, 2007; Nowicki, 2003; Sullivan et al., 2015). Research suggests that positive social interactions between students with and without disabilities have the potential to contribute to social, emotional, and academic development (Brown, Odom, \& McConnell, 2007; Killen \& Copland, 2011) including social well-being (Prinstein \& Dodge, 2008), increase self-concept (Pijl \& Frostad, 2010) and academic skills such as language development (Boyd, Conroy, Asmus, McKenney, \& Mancil, 2008; Rubin, Bukowski, \& Parker, 1998). However, while there is a body of research that characterizes the frequency and types of interactions between SWOD and SWD as noted above, remarkably little is known about where the breakdown occurs in their interactions and why.

Contemporary views no longer attribute social interaction issues solely to the skill deficits of SWD (Forness \& Kavale, 1991; Gresham, 1992; Vaughn, Elbaum, \& Boardman, 2001). Rather, studies have demonstrated that other factors, such as homophily (Farmer \& Farmer, 1996; Kalymon, Gettinger, \& Hanley-Maxwell, 2010; Killen, Rutland, \& Jampol, 2009), negative peer perceptions of disability and accommodations (Salend \& Duhaney, 1999; Sullivan et al., 2015), perceived academic ability (Plata, Trusty, \& Glasgow, 2005), as well as teacher attitudes and behavior (Cook, 2001; Woodcock \& Vialle, 2016), can influence social relations between students with and without disabilities. Thus, while social competency may play a role in general education students' decisions not to seek out peers with disabilities, it does not offer a sufficient explanation for the low frequencies of social engagement that are typical in many classrooms. Research is needed to better understand why SWOD tend not engage socially with their classmates who have disabilities within academic settings. 
Knowing why is critical to the development of intervention and support strategies that can assist teachers in creating classrooms where SWD are effectively integrated academically and socially.

It is important to recognize that the extent to which SWD are socially included within and outside of school is, to a large extent, dependent upon whether SWOD make an effort to interact with them. To date, few studies have examined factors associated with typical students' choices to interact with their peers with disabilities in early adolescence. Only one study was found that explicitly examined factors related to student intentions to socialize with peers with disabilities, as well as their actual socializing behavior (Roberts \& Smith, 1999). Additional research is needed to identify which factors most directly influence social overtures by SWOD in classrooms that include peers with disabilities. Such information may help schools take proactive steps to ensure that SWD are both socially, and academically, included in the fabric of middle school.

\subsection{Focus of the Study: Social Interactions and Initiations}

According to Underwood \& Rosen (2011), social interaction is a process that is comprised of separate levels and forms. Conceptually, three interrelated levels exist with each level distinct from the others. The individual level refers to the characteristics of the student and what they bring to interactions with peers, such as social skills, needs, and personality. The second level is interactional in nature and is used to describe what happens between students - what they do with each other, such as talk or engage in a teacher- initiated activity. These shared experiences provide a foundation for the third level-relationships. These are enduring patterns of interactions between students that are arranged around themes, roles, or shared views. In this conceptualization, forms of interaction are described as positive, neutral, or negative. Positive and neutral forms of interaction, such as promoting a peer's involvement in class activities or offering assistance, are key components of peer-based academic processes, such as collaborative learning. Without positive and fruitful occurrences at the first two levels, the third level of relationships cannot occur.

A social interaction originates with an intention to engage with another student, the actual behavior of initiating an interaction, and receipt of a response from the person to whom the overture was made (Delano \& Snell, 2006; Guralnick, Neville, Hammond, \& Connor, 2007; Yirmiya et al., 2006). Within this study, we were specifically interested in the positive initiations made by SWOD towards their peers with mild disabilities, and the factors that bring the student to want to make those overtures. Social initiations can be measured in terms of their form (verbal or gestural communication, facial expression, or physical contact), frequency, and valence (positive or negative). The differential influence of contextual, attitudinal, and experiential factors needs to be examined to truly understand the complex nature of social engagement.

\subsection{Conceptual Framework}

The Theory of Planned Behavior (TPB) (Fishbein \& Ajzen, 2010) was adopted as a conceptual framework to guide the examination of student behavior towards their peers. The Theory of Planned Behavior (TPB) has been utilized extensively to understand and predict various social behaviors, and considerable evidence has emerged to support its tenets. It posits that intentions are the best single predictor of a clearly identified behavior. Intentions to act in a particular manner are governed by three constructs: attitudes toward performing the behavior, normative pressure perceived to perform the behavior, and the control a person believes they have to perform the behavior. Measurement of the components of the model through interviews, surveys, and observations provide inferences about the likelihood of an individual performing a specific behavior. Within the domain of attitude-behavior research, the model has been extensively applied in a variety of contexts where it has been used to successfully predict a range of social intentions and behaviors (Bracke \& Corts, 2012; Fishbein \& Ajzen, 2010; Teo, 2012).

\subsection{Influences on Intentions and Actions}

Research from both general and special education suggest there are multiple factors that can influence students' social engagement in schools. Students with positive histories of exposure, experiences, and environments that respect individual differences are more likely to engage with peers who are different from themselves (Brown, Kuntz, Lysaght, \& Burge, 2011; Hamm, 2000; Kalymon et al., 2010). Additionally, personal experiences and relationships with persons who have disabilities have also been shown to have an effect on both attitudes and actions of children (Kennedy, Cushing, \& Itkonen, 1997; Krajewski \& Flaherty, 2000; McManus, Feyes, \& Saucier, 2011).

Multiple studies have also shown that students with more positive attitudes or beliefs about disabilities are more willing to interact with peers with a disability, while less positive thoughts and feelings by SWOD may interfere with and hinder positive interactions between students with and without disabilities (Kalymon et al., 2010; 
Litvack, Ritchie, \& Shore, 2011; Siperstein, Parker, Bardon, \& Widaman, 2007). Further, there is general agreement that social environments, and the norms within them, can strongly influence people's behavior (Bronfenbrenner, 1977; Fishbein \& Ajzen, 2010).

Studies have also shown that the culture of the family within the home shapes understanding and perceptions of disability. These values and norms have been found to impact the beliefs and attitudes of children (Halle, Costes, \& Mahoney, 1997; Maddock, Friel, \& Friel, 2009). Like family contexts, schools present differing expectations or norms that can impact student behavior generally, and opportunities for interaction between students with and without disabilities (Carter et al., 2008; Evans, Salisbury, \& Palombaro, 1992). Intentionality has emerged as a factor directly related to the actual performance of social behavior in adolescents. For example, Hardy, Dollahite, Johnson, \& Christenesen (2015) examined the role of motivation in relation to pro- and anti-social behavior by adolescents and found that the most critical factor in predicting pro-social behavior was intentionality. This finding suggests that adolescents' desire to establish themselves as independent actors may mitigate some of the effects of socio-cultural norms.

The inclination to socially engage with someone who is different from oneself is neither a linear, nor a simplistic event. Multiple forces play a role in the formation of the attitudes, beliefs, expectations, and intentions to engage. While existing descriptive studies have examined the social interactions of students with disabilities and their peers without disabilities in general education classrooms, they have not delved deeper into the underlying mechanism or forces that occasion action. Remarkably little is known about the factors that predict social initiations towards SWD, particularly in middle school. Further, no studies reported using direct observation of students' actual behavior as a means of understanding social engagement. The current study was undertaken to explore how multiple factors influenced social engagement in middle school classrooms. Specifically, we examined relationships between students' attitudes, perceptions of family and school norms, as well as perceived behavioral control and students' intentions to engage with and initiate socially towards peers with disabilities. The following research questions were answered in this study:

1) To what extent do SWOD in middle school classrooms initiate social initiations towards their peers with and without mild disabilities?

2) How do attitudes, perceptions of norms, and perceived efficacy (behavioral control) of SWOD influence student intentions to engage with and initiate socializing behavior towards peers with mild disabilities?

\section{Method}

\subsection{Participants and Setting}

The investigation was conducted in two public middle schools in a suburban school district in a Midwestern state in the US. Seventh grade general education classrooms in the district's two middle schools were the primary setting. Enrollment in the participating classrooms averaged 26 total students per classroom (range $=20$ to 29 , $\mathrm{SD}=2.96$ ), with an average of 5 students with Individualized Education plans (IEP) (range 1 to 9, SD 3.04). Three math classrooms, three language arts/reading classrooms, one science classroom, and one life skills classroom served as contexts for this study. All classes were taught by a single general education teacher and utilized a variety of instructional formats that naturally allowed for students with and without disabilities to interact. All students who were enrolled in a seventh-grade general education classroom that included at least one student with an IEP were eligible to participate in the study. Although a total of 171 seventh-grade students gave their assent, only 76 also received permission from their parent(s) to participate. The final participant sample consisted of 68 SWOD and 8 SWD (see Table 1). Students categorized as having a disability were identified through the district's assessment process with subsequent development of an IEP by their multi-disciplinary team, unless the student transferred in from another district with an active IEP. Of these eight students, one was also diagnosed with attention deficit hyperactivity disorder (ADHD), two were assessed as having a math disability, and six had an assessed reading disability. All SWD spent a minimum of $80 \%$ of their day in general education classes, with time outside the classroom spent in individualized or small group instruction delivered by a special education teacher.

The district served approximately 7,200 students across eight schools with nearly $70 \%$ of students receiving free or reduced-price lunch. The district's student population was approximately $20 \%$ Non-Hispanic White, $70 \%$ Hispanic, 5\% African American, 1.5\% Asian, and 1.5\% multi-racial/ethnic. Students with IEPs represented about $13 \%$ of the total population, and students who were eligible for bilingual education comprised almost $25 \%$ of the total enrollment. 
Table 1. Student demographics

\begin{tabular}{lllll}
\hline & \multicolumn{2}{c}{ Students with Disabilities } & \multicolumn{2}{c}{ Students without Disabilities } \\
\hline$n \quad 3$ & $10.5 \%$ & 68 & $89.5 \%$ \\
Gender & & & & \\
$\quad$ Male & 3 & $37.5 \%$ & 23 & $33.8 \%$ \\
$\quad$ Female & 5 & $62.5 \%$ & 45 & $66.2 \%$ \\
Age & & & & \\
$\quad 12$ & 6 & $75 \%$ & 42 & $61.8 \%$ \\
$\quad 13$ & 2 & $25 \%$ & 26 & $38.2 \%$ \\
Ethnicity & & & & \\
$\quad$ Caucasian & 2 & $25 \%$ & 12 & $17.6 .2 \%$ \\
$\quad$ Hispanic & 3 & $37.5 \%$ & 50 & $73.5 \%$ \\
$\quad$ African American & 3 & $37.5 \%$ & 6 & $8.8 \%$ \\
\hline
\end{tabular}

\subsection{Rating Scale Measures}

A multi-part student questionnaire based on the TPB was administered once to each participating student. This questionnaire consisted of five sections that solicited demographic information (including prior experiences with a person with a disability), as well as responses to items designed to assess the students' attitudes, perceived norms, perceived behavioral control and behavioral intentions towards interacting socially with peers with disabilities. These items map directly to the constructs in the TPB.

Four rating scales included in the student questionnaire were subscales or adapted scales from psychometrically valid measures. The Chedoke-McMaster Attitudes Towards Children with Handicaps (CATCH) Scale (Rosenbaum, 1986) measured the attitudinal and subjective norm components of the TPB framework. This scale consists of 36-items measured on a 5-point Likert scale ranging from 1 (strongly disagree) to 5 (strongly agree). Twelve items devoted to each of the three dimensions of attitudes: affective (e.g., "I would enjoy being with a student with a disability"), cognitive, (e.g., "Students with a disability don't like to make friends"), and behavioral (e.g., "I would talk to a student with a disability that I didn't know"), were divided equally into positive and negatively worded statements. In addition to reporting acceptable reliability and validity, including a coefficient alpha of .90 , a detailed description of the initial validation process is also available (Rosenbaum, Armstrong, \& King, 1988; Vignes, Coley, Grandjean, Godeau, \& Arnaud, 2008). The abbreviated version, utilized for the attitude component of the questionnaire, included 18 total items, six from each of the dimensions. Six items from the behavioral component of the CATCH scale were modified for use with the subjective norm construct. To assess whether peers perform the behaviors, the stem "My friends would", was inserted at the beginning of each item. Similarly, to assess social pressure from important others, the stem "My parents or teacher would want me to", was added to each of the six items.

The Children's Self-Efficacy Scale social self-efficacy subscale (Bandura, 1989) and the Perceived Social Efficacy scale (Patrick, Hicks, \& Ryan, 1997) were used to measure the perceived behavioral component. Both measures utilize a Likert type rating scale ( 7 and 5 point, respectively), and psychometric studies of both measures report good internal consistency. Miller, Coombs, \& Fuqua (1999) reported coefficient alpha of 0.83 for subscale of the Children's Self-Efficacy Scale. Patrick et al. (1997) reported a coefficient alpha of .72 for the Perceived Social Efficacy scale. Four items from each scale that were particularly relevant to the focus of this study were included in the questionnaire and adapted by the addition of the phrase "with a disability", and items presented as a question were rephrased as statements.

The Behavioral Intentions Scale (Siperstein et al., 2007) was used to measure the intentions component of the TPB framework. The full scale consists of 12 questions that assess intentions to interact with peers with an intellectual disability. The authors report strong reliability with a coefficient alpha of 0.93 . Six items related to school activities were used from this scale and the term, "student with an intellectual disability" was replaced with "student with a disability". Items were measured on a 4- point Likert-type scale (1-Yes, 2- Probably Yes, 3Probably No, 4- No) to measure the intentions of SWOD to socialize with their peers with disabilities.

\subsection{Observational Measures}

The incorporation of direct observation is a unique and important feature of this study because the antecedents for socializing, rather than the process of socializing, served as the focus of the present study. Social initiations between students with and without disabilities were used as the primary index of socializing. The measurement of social initiations often includes its form (verbal or gestural communication, facial expression, or physical 
contact), frequency, and valence (positive or negative). Examples can include initiating conversations, offering affirming verbal statements, and providing academic or physical assistance. Socializing has an inherently positive connotation and is not typically used to describe interactions that are negative, harmful, or destructive (Eisenberg et al., 1997; Masten \& Coatsworth, 1998; Rothbart \& Bates, 1998). Given the typically positive nature of socializing behaviors, this study focused on positive social initiations as the primary dependent variable.

Observations of student initiations occurred six times per classroom during the study using selected components of two observational tools - the Social Interaction Observation Form (SIOF) (Storey \& Horner, 1991; Storey \& Knutson, 1989) and the Adapted Individual Social Behavior Scale (ISBS) (Guralnick et al., 2007). Interobserver agreement on the SIOF in previous studies ranged from $76 \%$ to $100 \%$, with a mean of $93.6 \%$ and a Kappa of .89 . For this study, five categories of behavior that could be considered initiations and socialization were selected from the SIOF. The second tool, the ISBS also had acceptable reliability with an overall mean agreement of $88 \%$ (range 57-100\%) and a kappa of .75. Four categories of initiations were selected from the ISBS. Table 2 contains operational definitions of the coding categories. Examples provided within the categories were modified to match behaviors present during the school day for middle school students.

Table 2. Operational definitions for social initiations towards students with disabilities

Providing assistance (A): Giving any help to student to complete a task. This can be verbal or physical in nature. For example, Mike opens the classroom door for student.

Providing social amenities (SA): Giving any verbal or nonverbal behaviors that are associated with social amenities, such as saying "Hey, how are you doing?"

Providing social compliments (SC): Giving any verbal or nonverbal behaviors that are positive and reinforcing to others. For example, Mike says to student, "Great job today".

Non-school related conversation (NSC): Initiation of a verbal exchange beyond social amenities that is non-school related. For example, Mike asks student what $\mathrm{s} / \mathrm{he}$ did last weekend or if s/he saw a new movie.

Joins peer engaged in activity (JP): Student is engaged in a specific activity and is deliberately joined by Mike in that activity. For example, Mike sees student in the library section of the classroom looking for a book and joins student in this task.

Attempts to gain attention of peer (GA): Any attempt to gain the attention of a peer in a neutral or positive manner. An attempt may be verbal, nonverbal or physical in nature. For example, Mike taps the student sitting in front of him on the shoulder.

Other $(\mathrm{O})$ : Any positive social behavior initiation that cannot be classified to the categories described above.

Unknown (U): Unable to hear initiation or clearly distinguish what happened.

Teacher directed (TD): Any of the above categories, but done in the context of a request by the teacher. For example, Teacher asks Mike to provide assistance to student and Mike then does this.

\subsection{Procedures}

After securing parent permission and student assent, half of the participating classrooms began study activities with the administration of the questionnaire, while the other classrooms began with classroom observation. This was done to minimize the possible influence of order effects.

\subsubsection{Observational Data Collection}

Data were collected for the entire 45 minute class period. A photo seating chart was used to determine the identity of target students with and without disabilities. Clusters of students, defined as those seated in direct proximity to each other, were identified for observation. Students in direct proximity were most able to initiate contact. These target students were kept constant for the duration of the study. The SIOF was used to record initiations for the class period with the observer's focus alternating between the target student with disabilities and the target student without disabilities every two minutes. The order in which students were observed rotated between an A-B-A-B and a B-A-B-A pattern throughout the study. All initiations were entered onto a recording form as they occurred during the class period. 


\subsubsection{Student Questionnaire}

The student questionnaire was administered during the first 15-20 minutes of the class period. Following a brief explanation by the investigator, printed surveys were distributed to all students for whom parental permission and assent was received. Students who did not assent or receive parental permission were asked to work quietly on other work at their seat during this time. SWD who provided assent and consent completed a similar, adapted printed questionnaire that assessed their attitudes and intentions to interact with their classmates. Data from these latter questionnaires were not analyzed for this study.

\subsection{Data Analysis}

Statistical Package for the Social Sciences (SPSS) software was utilized to enter and analyze data. Frequency data from direct observations, along with data from student questionnaires, were analyzed using descriptive statistics, correlational analyses, and analysis of variance to determine if gender, previous experience with an individual with a disability, attitudes, perceptions of norms, and perceived behavioral control were associated with intentions or actual initiations by SWOD towards SWD. Multiple linear regression was computed to determine if attitudes, perceptions of norms, and perceived behavioral control predicted the intention or actual behavior of SWOD towards their peers with disabilities.

\subsubsection{Reliability}

Reliability calculations were computed for both the survey and observational components of the study. Cronbach's Alpha, a measure of internal consistency, was computed for each construct in the student questionnaire. The coefficient alpha of the student questionnaire was .92. All of the subscales and the questionnaire as a whole were considered to be sufficiently internally consistent because the coefficient alphas exceeded .70 (Nunnally \& Bernstein, 1994; Tabachnick \& Fidell, 2007).

Reliability for the observational component of the study was ascertained using interobserver agreement (IOA). IOA was assessed for $27 \%$ of the classroom observations with each classroom co-observed at least twice. The primary observer was the first author of the study. A veteran teacher with doctoral level experience in observational data collection served as co-observer for this study. The co-observer was trained over a week-long period prior to going into participating classrooms. This consisted of reading and discussion of observational literature and the coding instrument, followed by independent coding of classroom videos selected by the PI. IOA during training was $83 \%$, while overall non-occurrence agreement for the training sessions was $93 \%$. IOA agreement was calculated by dividing the number of intervals during which both data collectors agreed on the occurrence of a behavior by the sum of the number of intervals during which either one or both of the data collectors recorded the occurrence of the behavior, multiplied by 100. Percentage of nonoccurrence agreement was calculated similarly. Total IOA agreement for all 10 classroom observations was $87.3 \%$, while interobserver non-occurrence agreement for all 10 classroom observations was $98.7 \%$. Overall IOA agreement averaged $93 \%$.

\section{Results}

\subsection{Frequency of Social Initiations}

To calculate the extent of positive initiations, the nine types of behaviors recorded during the six classroom observations for each participating class were summed and averaged. Classrooms averaged a rate of 2.1 positive initiations towards the target SWD per class period, with a range from 0 to $8(S D=1.92)$ (Note 1). The average number of initiations per class period towards the target SWOD was 3.5, with a range of 0 to $10(S D=2.80)$. An independent -samples t-test was conducted to compare the frequency of initiations towards SWD and SWOD across classroom observations. Results indicated that there were significant difference in the overall frequency of initiations between the two groups $(t(56)=2.17, p=.04)^{1}$.

\subsection{Factor Relationships to Behavior}

Bi-variate Pearson correlations were calculated to examine the relations between each of the framework constructs (attitude, perceived behavioral control, and subjective norm) and intention to initiate and observed initiated behavior. As shown in Table 3, attitude, perceived behavioral control and subjective norm were all positively correlated with intention. Additionally, all three constructs were highly correlated with each other. However, none of the correlations between the constructs and initiations were statistically significant. Additionally, the correlation between intent and observed initiations was not significant, $r(26)=.04, \mathrm{p}=.85$. 
Table 3. Correlations between predictor and outcome variables

\begin{tabular}{lllllll}
\hline & \multicolumn{3}{c}{ Intent to Initiate } & \multicolumn{4}{c}{ Observed Initiations } \\
& $n$ & Pearson Correlation & Sig. (2 tailed) & $n$ & Pearson Correlation & Sig. (2 tailed) \\
\hline Attitude & 68 & $.630^{* *}$ & .000 & 26 & .337 & .092 \\
Behavioral Control & 68 & $.621^{* *}$ & .000 & 26 & .207 & .311 \\
Subjective Norm & 68 & $.626^{* *}$ & .000 & 26 & .124 & .547 \\
\hline
\end{tabular}
Note. $* * \mathrm{p}<.001$.

\subsection{Contributions to Intent and Actual Behavior}

A multiple linear regression analysis was performed to determine the magnitude of the overall relationship between intention and action, as well as between intention and attitude, perceived behavioral control, and subjective norm. The regression analysis was run with and without the demographic variable of previous experience due to its association with the constructs. However, because it did not add to the model, the analysis reported here does not include it. Intention as a continuous variable was utilized as the dependent variable. Linear combination of all three constructs were significantly related to the intention index, $F(3,64)=21.51, p$ $<.001$. The multiple correlation coefficient was .71, indicating that approximately $50 \%$ of the variance of intentions to initiate socializing behavior towards students with mild disabilities can be accounted for by the linear combination of attitudes, perceived behavioral control, and subjective norm. The analysis revealed that attitude significantly predicted intention, $\beta=.29, \mathrm{p}<.05$, as did subjective norm, $\beta=.26, \mathrm{p}<.05$. Perceived behavioral control $(\beta=.25, \mathrm{p}=.06)$ did not contribute significantly to the prediction of intentions.

An additional regression analysis was conducted to determine if attitudes, perceived behavioral control, and subjective norm would be predictive of observed initiations. Consistent with bivariate analyses of the framework variables and student initiations, these analyses failed to yield significant results.

\section{Discussion}

Several findings emerged from this study. Our primary finding was that, despite strong intentions, SWOD did not move to act on those intentions to engage with their classmates who had disabilities. The TPB framework posits that strong intentions that result from favorable attitudes, subjective norm, and perceived behavioral control should result in performance of the behavior, and that strong intention should increase the likelihood of actual performance of the behavior. However, this did not occur in our study. Despite students' strongly stated intentions, there was no association between intentions and observed initiations. This finding was unexpected because extant research reports a relationship between expressed intent and actual behavior. However, within the particularly limited research examining multiple factors relationships to intentions and actual actions between students with and without disabilities in school settings, only weak relationships have been found between expressed intentions and observed behavior. It is possible that in cases where attitudes, norms, and behavioral control do not each sufficiently contribute to intentions, the relationship between intentions and actual behavior is absent.

Despite the absence of a relation between expressed intention and action, student attitudes and norms emerged as the two variables most related to student intentions. This finding suggests that student's attitudes towards peers with disabilities and their perception of either school or home norms influenced their intentions to interact with their peers with disabilities. This finding is consistent with literature that suggests the behaviors modeled by educators and parents influence the beliefs and attitudes of students, though not necessarily their actions (e.g., Kiuru et al., 2012; Maddock et al., 2009). Responses from the students in our sample indicated that both self-efficacy and prior experience were also related to intentions. However, when considered in conjunction with student attitudes and norms, their effect did not increase the prediction of student intentions. The disjuncture between professed beliefs, attitudes, and norm recognition and true action is consistent with period of early adolescence during which time children's development of personal beliefs and identity is strongly influenced by others. The dissonance between what students said versus what they did is also reflective of the do-say, say-do psychological research literature on correspondence (Israel, 1978). While the social interaction dynamic in middle school is complex, understanding where the "breakdown" occurs between professed intentions and actual behavior may help bridge the divide between students with and without disabilities in general education classrooms.

In-depth inspection of the data revealed tenable rival explanations for our findings. Student responses on the intention measure clustered at the maximum possible rating, limiting the extent to which they could co-vary with observed behavior which was more variable from student to student. It is possible that the student questionnaire, 
specifically the very direct measures of intent, elicited socially desirable responses from students. It is also possible that students had true strong intentions, but did not act on them. Choosing not to act could be due to various factors, including a lack of opportunity or a change in their motivation. In addition, observations were confined to mostly academic classes, whereas the behaviors referenced in the intention scale of the student questionnaire were not all necessarily confined to academic classes and could be performed throughout the school day. It is reasonable to believe that students may have responded to the intention items in a more global manner than their actual observed behavior implied.

There may have also been a discrepancy between students' perceptions of a student with a disability and actual SWD in their classes. As seen in Kalymon's (2010) study, students of this age were not able to discriminate between students without disabilities and students with high incidence disabilities. In the present study, while students with more moderate and severe disabilities were enrolled in the school, only students with mild disabilities were present in the classrooms in which observations were conducted. It is possible that student participants envisioned peers with more visible disabilities while completing the questionnaire.

\subsection{Limitations of the Study}

The results of the current study need to be interpreted in light of several limitations. First, the use of convenience sampling to recruit students from two schools within a single district contributed to a context, as well as a sample, that may not be representative of middle schools writ large. Additionally, the cultural/linguistic diversity of the student sample may limit generalizability of findings to those districts with similar demographic composition. Classroom instruction in these schools was largely teacher centered, limiting the opportunity for students to interact. Therefore, what was observed might not be a true representation of how students behave in unstructured school or non-school social situations. Although students with a range of disabilities attended these schools, the majority of SWD in the participating general education classrooms had mild disabilities. There is, therefore, limited ability to generalize results to other disability groups and schools that include students with the full range of disabilities in general education classes, including those with significant support needs. Second, the survey component of the study relied on student self-report. Given the topic of the study, it is possible that students may have been inclined to answer survey items with responses they believed to be more socially desirable, regardless of whether it was accurate and truthful. Lastly, the study was conducted over a relatively short period of time, making it difficult to determine the degree to which the observed social behavior was typical.

\subsection{Implications for Practice}

This study focused on the social initiation behavior of middle school SWOD toward their peers with disabilities. One of the promising findings was students' strongly stated intentions to initiate social interactions with peers. However, our data indicated a disconnect between students' stated intentions and their actual behavior. Even though students expressed strong intentions to socialize with students with mild disabilities, their actual observed behavior was more variable. It is quite possible that students have strong intentions to initiate, but only with additional opportunities and structured support are they able to follow through on these intentions. Thus, we believe there is a need to identify instructional configurations, strategies, and materials that help teachers provide multiple opportunities for students with and without disabilities to have meaningful, reciprocal, and equal-status interactions in the classroom. Evidence-based strategies, such as shared learning tasks, small group arrangements, and inquiry projects may foster positive attitudes and interactions across academic content areas especially when facilitated by teachers with high self-efficacy beliefs and positive attributions of students with disabilities (Jordan, Glenn, \& McGhie-Richmond, 2010; Woolfson \& Brady, 2009). Additionally, integrating forms of technology into the curriculum, especially within team-based or group work activities, can further support collaborative interactions (e.g., Jonassen, Howland, \& Marra, 2011; Shell et al., 2005). With targeted administrative support, shifts in school norms and intentional instructional practices can enhance the meaningful incorporation of students with diverse needs and abilities into the social and academic fabric of the school (Salisbury \& McGregor, 2002).

\subsection{Recommendations for Future Research}

There are several areas for future exploratory and intervention research that emerged from this investigation. First, future research should be conducted with larger sample sizes, across multiple grade levels, and school contexts. Doing so would allow for a more comprehensive picture of students without disabilities' intentions and behaviors, and enhance the representativeness of study results. Second, it is not possible to determine the reasons students with mild disabilities in this sample experienced less positive initiations. Future research should include items that explore students' reasoning and beliefs about why they choose to interact less with SWD. Similarly, although discrete initiations offer one indication of students' dispositions, additional information should be 
collected regarding the extent to which initiations contribute to social acceptance, a sense of belonging, and friendships, each of which has been cited as outcomes of inclusive schools (Evans, Salisbury, Palombaro, Berryman, \& Hollowood, 1992; Schwartz, 2000). Such information may help in the development of interventions that enhance the school social experiences of SWD. This type of intervention research is important because of the known influences of social experiences among students with high incidence disabilities and their future academic and social outcomes (Cutts \& Sigafoos, 2001). Studies that examine how interactions between students with and without disabilities are related to other measures of school outcomes, such as retention, graduation, higher education, and job placement, are also warranted. Finally, comparative research is needed that examines whether patterns found in this study are evident in classrooms where students with mild disabilities and students with more significant support needs are educated. This may help identify specific characteristics of SWD that act as barriers to social initiations or characteristics that are more readily understood by peers without disabilities that perhaps elicit greater acceptance of differences.

Despite advances in the social and academic inclusion of SWD in general education classrooms, the social acceptance of SWD in schools remains an area of significant concern. This study illustrates that multiple factors impact the likelihood that social interactions will occur among students. Our findings offer important insights into where disconnects may lie as we try to understand the limited social inclusion of students with mild disabilities in middle grades. Interventions designed to foster positive, meaningful social interactions in middle schools will need to include assessments of both observed behavior and reported intentions and perceptions. Doing so may make a qualitative difference in the social inclusion of SWD in schools.

\section{References}

Bandura, A. (1989). Multidimensional scales of perceived self-efficacy. Test. Stanford University. Stanford,CA.

Boyd, B. A., Conroy, M. A., Asmus, J. M., McKenney, E. L. W., \& Mancil, G. F. (2008). Descriptive analysis of classroom setting events on the social behaviors of children with autism spectrum disorder. Education and Training in Developmental Disabilities, 43(2), 186-197.

Bracke, D., \& Corts, D. (2012). Parental involvement and the theory of planned behavior. Education, 133(1), 188-201.

Bronfenbrenner, U. (1977). Toward an experimental ecology of human development. American Psychologist, 32(7), 513-531. http://dx.doi.org/10.1037/0003-066X.32.7.513

Brown, Kuntz, H. O., Lysaght, R., \& Burge, P. (2011). Students' behavioural intentions towards peers with disability. Journal of Applied Research in Intellectual Disabilities, 24(322-332). http://dx.doi.org/10.1111/j.1468-3148.2010.00616.x

Brown, Odom, S. L., \& McConnell, S. R. (Eds.). (2007). Social competence of young children: Risk, disability, and intervention. Baltimore, MD: Paul H. Brooks.

Carter, E. W., Sisco, L. G., Brown, L., Brickham, D., \& Al-Khabbaz, Z. A. (2008). Peer interactions and academic engagement of youth with developmental disabilities in inclusive middle and high school classrooms. American Journal on Mental Retardation, 113(6), 479-494. http://dx.doi.org/10.1352/2008.113:479-494

Cook, B. G. (2001). A comparison of teachers' attitudes toward their included students with mild and severe disabilities. The Journal of Special Education, 34(4), 203-213. https://doi.org/10.1177/002246690103400403

Cutts, S., \& Sigafoos, J. (2001). Social competence and peer interactions of students with intellectual disability in an inclusive high school. Journal of Intellectual \& Developmental Disability, 26(2), 127-141. http://dx.doi.org/10.1080/13668250020054440

Delano, M., \& Snell, M. E. (2006). The effects of social stories on the social engagement of children with autism. Journal of Positive Behavior Interventions, 8(1), 29-42. http://dx.doi.org/10.1177/10983007060080010501

Dyson, L. L. (2003). Children with learning disabilities within the family context: A comparison with siblings in global self-concept, academic self-perception and social competence. Learning Disabilities Research \& Practice, 18(1), 1-9. 10.1111/1540-5826.00053

Eisenberg, N., Guthrie, I. K., Fabes, R. A., Reiser, M., Murphy, B. C., Holgren, R., ... Losoya, S. (1997). The relations of regulation and emotionality to resiliency and competent social functioning in elementary school children. Child Development, 68(2), 295-311. http://dx.doi.org/10.2307/1131851 
Estell, D. B., Jones, M. H., Pearl, R., Van Acker, R., Farmer, T. W., \& Rodkin, P. C. (2008). Peer groups, popularity, and social preference: Trajectories of social functioning among students with and without learning disabilities. Journal of Learning Disabilities, 4l(1), 5-14. https://doi.org/10.1177/0022219407310993

Evans, I. M., Salisbury, C., \& Palombaro, M. (1992). Peer interactions and social acceptance of elementary-age children with severe disabilities in an inclusive school. Journal of the Association for Persons with Severe Handicaps, 17(4), 205-212. https://doi.org/10.1177/154079699201700401

Farmer, T. W., \& Farmer, E. M. (1996). The social relationships of students with exceptionalities in mainstream classrooms: Social networks and homophily. Exceptional Children, 62, 431-450. https://doi.org/10.1177/001440299606200504

Fishbein, M., \& Ajzen, I. (2010). Predicting and changing behavior: The reasoned action approach. New York, NY: Psychology Press.

Forness, S. R., \& Kavale, K. A. (1991). Social skills as a primary learning disability: A note on problems with ICLD diagnostic criteria. Learning Disabilities Research \& Practice, 6, 44-49.

Gresham, F. M. (1992). Social skills and learning disabilities: Causal, concomitant, or correlational. School Psychology Review, 21, 348-360.

Guralnick, M. J., Neville, B., Hammond, M. A., \& Connor, R. T. (2007). Linkages between delayed children's social interactions with mothers and peers. Child Development, 78(2), 459-473. http://dx.doi.org/10.1111/j.1467-8624.2007.01009.x

Halle, T. G., Costes, B. K., \& Mahoney, J. L. (1997). Family influences on school achievement in low-income African American children. Journal of Educational Psychology, 89(3), 527-537. http://dx.doi.org/10.1037/0022-0663.89.3.527

Hamm, J. V. (2000). Do birds of a feather flock together? The variable bases for African American, Asian American, and European American adolescents' selection of similar friends. Developmental Psychology, 36(2), 209-219. http://dx.doi.org/10.1037/0012-1649.36.2.209

Hamovitch, B. (2007). Hoping for the best: "Inclusion" and stigmatization in a middle school. In S. Books (Ed.), Invisible children in the society and in schools (3rd ed., pp. 263-281). Mahwah, NJ: Lawrence Erlbaum.

Hardy, S. A., Dollahite, D. C., Johnson, N., \& Christensen, J. B. (2015). Adolescent motivations to engage in pro-social behaviors and abstain from health-risk behaviors: A self-determination theory approach. Journal of Personality, 83(5), 479-490.

Israel, A. C. (1978). Some thoughts on correspondence between saying and doing. Journal of Abnormal Child Psychology, 11(2), 271-276. https://doi.org/10.1901/jaba.1978.11-271

Jonassen, D. H., Howland, J., \& Marra, R. (2011). Meaningful Learning with Technology (4th edition). Boston: Pearson.

Jordan, A., Glenn, C., \& McGhie-Richmond, D. (2010). The supporting effective teaching (SET) project: The relationship of inclusive teaching practices to teachers' beliefs about disability and ability, and about their roles as teachers. Teaching and Teacher Education, 26(2), 259-266. https://doi.org/10.1016/j.tate.2009.03.005

Kalymon, K., Gettinger, M., \& Hanley-Maxwell, C. (2010). Middle school boys' perspectives on social relationships with peers with disabilities. Remedial and Special Education, 31(4), 305-316. http://dx.doi.org/10.1177/0741932508327470

Kavale, K. A., \& Forness, S. R. (1996). Social skills deficits and learning disabilities: A meta-analysis. Journal of Learning Disabilities, 29(3), 226-237. https://doi.org/10.1177/002221949602900301

Kennedy, C. H., Cushing, L. S., \& Itkonen, T. (1997). Social contacts and friendship networks of students with severe disabilities. Journal of Behavioral Education, 7(2), 167-189. http://dx.doi.org/10.1023/A:1022888924438

Killen, M., \& Copland, R. J. (Eds.). (2011). Social development in childhood and adolescence: A contemporary reader. New York, NY: Wiley. 
Killen, M., Rutland, A., \& Jampol, N. S. (2009). Social exclusion in childhood and adolescence. In K. H. Rubin, W. M. Bukowski, \& B. Laursen (Eds.), Handbook of Peer Interactions, Relationships, and Groups. New York: Guilford Press.

Kiuru, N., Poikkeus, A. M., Lerkkanen, M. K., Pakarinen, E., Siekkinen, M., Ahonen, T., \& Nurmi, J. E. (2012). Teacher-perceived supportive classroom climate protects against detrimental impact of reading disability risk on peer rejection. Learning and Instruction, 22, 331-339. http://dx.doi.org/10.1016/j.learninstruc.2011.12.003

Krajewski, J., \& Flaherty, T. (2000). Attitudes of high school students toward individuals with mental retardation. Mental Retardation, $38(2), \quad$ 154-162. http://dx.doi.org/10.1352/0047-6765(2000)038<0154:AOHSST>2.0.CO;2_

Litvack, M. S., Ritchie, K. C., \& Shore, B. M. (2011). High- and average-achieving students' perceptions of disabilities and of students with disabilities in inclusive classrooms. Exceptional Children, 77(4), 474-487. https://doi.org/10.1177/001440291107700406

Maddock, J. W., Friel, J. C., \& Friel, L. D. (2009). Family influences and ecological context. In W. O'Donohue \& S. R. Graybar (Eds.), Handbook of contemporary psychotherapy: Toward an improved understanding of effective psychotherapy. Thousand Oaks, CA: Sage Publications. https://doi.org/10.4135/9781452224909.n6

Masten, A. S., \& Coatsworth, D. J. (1998). The development of competence in favorable and unfavorable environments: Lessons from research on successful children. American Psychologist, 53(2), 205-220. http://dx.doi.org/10.1037/0003-066X.53.2.205

McManus, J. L., Feyes, K. J., \& Saucier, D. A. (2011). Contact and knowledge as predictors of attitudes toward individuals with intellectual disabilities. Journal of Social and Personal Relationships, 28(5), 579-590. https://doi.org/10.1177/0265407510385494

Nowicki, E. A. (2003). A meta-analysis of the social competence of children with learning disabilities compared to classmates of low and average to high achievement. Learning Disability Quarterly, 26(3), 171-188. https://doi.org/10.2307/1593650

Nunnally, I. H., \& Bernstein, J. C. (1994). Psychometric theory. New York: McGraw-Hill.

Patrick, H., Hicks, L., \& Ryan, A. M. (1997). Relations of perceived social efficacy and social goal pursuit to self-efficacy for academic work. Journal of Early Adolescence, 17(2), 109-128. https://doi.org/10.1177/0272431697017002001

Pearl, R., Farmer, T. W., Acker, R. V., Rodkin, P. C., Bost, K. K., Coe, M., \& Henley, W. (1998). The social integration of students with mild disabilities in general education classrooms: Peer group membership and peer-assessed social behavior. The Elementary School Journal, 99(2), 167-185. http://dx.doi.org/10.1086/461921

Pijl, S. J., \& Frostad, P. (2010). Peer acceptance and self-concept of students with disabilities in regular education. European Journal of Special Needs Education, 25(1), 93-105. https://doi.org/10.1080/08856250903450947

Plata, M., Trusty, J., \& Glasgow, D. (2005). Adolescents with learning disabilities: Are they allowed to participate in activities? Journal of Educational Research, 98(3), 136-143. http://dx.doi.org/10.3200/JOER.98.3.136-143

Prinstein, M. J., \& Dodge, K. A. (Eds.). (2008). Understanding peer influence in children and adolescents. New York, NY: Guilford Press.

Roberts, C. M., \& Smith, P. R. (1999). Attitudes and behaviour of children twoard peers with disabilities. International Journal of Disability, Development, and Education, 46(1), 35-50. http://dx.doi.org/10.1080/103491299100713

Rosenbaum, P. L. (1986). Children's attitudes toward disabled peers: A self-report measure. Journal of Pediatric Psychology, 11(4), 517. http://dx.doi.org/10.1093/jpepsy/11.4.517

Rosenbaum, P. L., Armstrong, R. W., \& King, S. M. (1988). Determinants of children's attitudes toward disability: A review of evidence. Children's Health Care, 17(1), 32-39. http://dx.doi.org/10.1207/s15326888chc1701_5

Rothbart, M. K., \& Bates, J. E. (1998). Temperament. In W. Damon \& N. Eisenberg (Eds.), Handbook of child psychology (Vol. 3, pp. 105-176). Hoboken, NJ: John Wiley \& Sons Inc. 
Rubin, K. H., Bukowski, W. M., \& Parker, J. G. (1998). Peer interactions, relationships, and groups. In N. Eisenberg (Ed.), Handbook of child psychology (5th ed., Vol. 3, pp. 619-700). New York: John Wiley and Sons.

Salend, S. J., \& Duhaney, L. M. G. (1999). The impact of inclusion on students with and without learning disabilities and their educators. Remedial and Special Education, 20, 114-126. https://doi.org/10.1177/074193259902000209

Salisbury, C. L., \& McGregor, G. (2002). The administrative climate and context of inclusive elementary schools. Exceptional Children, 68, 259-274. https://doi.org/10.1177/001440290206800207

Shell, D. F., Husman, J., Turner, J. E., Cliffel, D. M., Nath, I., \& Sweany, N. (2005). The impact of computer supported collaborative learning communities on high school students' knowledge building, strategic learning, and perceptions of the classroom. Journal of Educational Computing Research, 33(3), 327-349. https://doi.org/10.2190/787L-BCBQ-20FN-FW6C

Siperstein, G. N., Parker, R. C., Bardon, J. N., \& Widaman, K. F. (2007). A national study of youth attitudes toward the inclusion of students with intellectual disabilities. Exceptional Children, 73(4), 435-455. https://doi.org/10.1177/001440290707300403

Storey, K., \& Horner, R. H. (1991). Social interactions in three supported employment options: A comparative analysis. Journal of Applied Behavior Analysis, 24(2), 349-360. https://doi.org/10.1901/jaba.1991.24-349

Storey, K., \& Knutson, N. (1989). A comparative analysis of social interactions of workers with and without disabilities in integrated work settings: A pilot study. Education and Training in Mental Retardation, 24(3), 265-273.

Sullivan, T. N., Sutherland, K. S., Lotze, G. M., Helms, S. W., Wright, S. A., \& Ulmer, L. J. (2015). Problem situations experienced by urban middle school students with high incidence disabilities that impact emotional and behavioral adjustment. Journal of Emotional and Behavioral Disorders, 23(2), 101-114. https://doi.org/10.1177/1063426614528243

Tabachnick, B. G., \& Fidell, L. S. (2007). Using multivariate statistics (5th edition). Boston, MA: Pearson Education.

Teo, T. (2012). Examining the intention to use technology among pre-service teachers: an integration of the technology acceptance model and theory of planned behavior. Interactive Learning Environments, 20(1), 3-18. https://doi.org/10.1080/10494821003714632

Underwood, M. K., \& Rosen, L. H. (Eds.). (2011). Social development: Relationships in infancy, childhood, and adolescence. New York, NY: Guilford Press.

Vaughn, S., Elbaum, B., \& Boardman, A. G. (2001). The social functioning of students with learning disabilities: Implications for inclusion. Exceptionality, 9(1/2), 47-65. https://doi.org/10.1080/09362835.2001.9666991

Vignes, C., Coley, N., Grandjean, H., Godeau, E., \& Arnaud, C. (2008). Measuring children's attitudes towards peers with disabilities: A review of instruments. Developmental Medicine \& Child Neurology, 50, 182-187. http://dx.doi.org/10.1111/j.1469-8749.2008.02032.x

Woodcock, S., \& Vialle, W. (2016). An examination of pre-service teachers' attributions for students with specific learning difficulties. Learning and Individual Differences, 45, 252-259. https://doi.org/10.1016/j.lindif.2015.12.021

Woolfson, L. M., \& Brady, K. (2009). An investigation of factors impacting on mainstream teachers' beliefs about teaching students with learning difficulties. Educational Psychology, 29(2), 221-238. https://doi.org/10.1080/01443410802708895

Yirmiya, N., Gamliel, I., Pilowsky, T., Feldman, R., Cohen, S. B., \& Sigman, M. (2006). The development of siblings of children with autism at 4 and 14 months: social engagement, communication, and cognition.

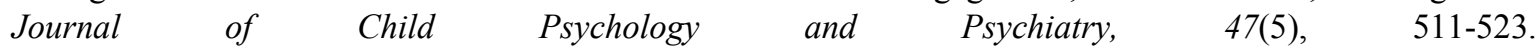
http://dx.doi.org/10.1111/j.1469-7610.2005.01528.x

\section{Note}

Note 1 . These statistics exclude 2 data points identified as outliers. 


\section{Copyrights}

Copyright for this article is retained by the author(s), with first publication rights granted to the journal.

This is an open-access article distributed under the terms and conditions of the Creative Commons Attribution license (http://creativecommons.org/licenses/by/4.0/). 